\title{
A PERFORMANCE DRAG QUEEN E SUAS REVERBERAÇÕES
}

\author{
DRAG QUEEN PERFORMANCE AND ITS REVERBERATIONS
}

\author{
Matheus Flauzino Oliari ${ }^{1}$ \\ Jesio Zamboni ${ }^{2}$
}

\begin{abstract}
Resumo: Apesar de existirem algumas conceituações que buscam abarcar o conceito de drag queen ou o que seria a performance drag, podemos entender essa forma de arte e expressão como fazer de caráter expansivo, sempre inovador. A montação, ato de construir e arquitetar o próprio corpo com acessórios, roupas, cosméticos e edições de imagem, consiste em um dos principais artifícios que permitem as drag queens construírem e alterarem a realidade de acordo com suas ambições e desejos. Além da montação, os movimentos, gestos, performances e gírias que envolvem a performance drag atravessam e são atravessadas pelas linhas de segmentaridade rígidas, linhas maleáveis e linhas de fuga e se presentificam em movimentos de desterritorialização e reterritorialização.
\end{abstract}

Palavras-chave: Drag queen; Deleuze e Guattari; performance; desterritorialização; linhas de fuga.

\begin{abstract}
Although there are some concepts that seek to encompass the concept of drag queen or what drag performance could be, we can understand this form of art and expression as an expansive type of action, always innovative. Editing, the act of building and architecting their own body with accessories, clothing, cosmetics and image editing, is one of the main devices that allow drag queens to build and alter reality according to their ambitions and desires. In addition to editing, the movements, gestures, performances and slang that surrounds drag performance can cross and are crossed by lines of rigid segmentarity, malleable lines and lines of flight, and present themselves in movements of deterritorialization and reterritorialization.
\end{abstract}

Keywords: Drag queen; Deleuze and Guattari; drag performance; deterritorialization; lines of flight.

Pessoas vestidas com plumas coloridas, brilhos, saltos, vestidos, maiôs e muita extravagância. Olhares penetrantes, profundos, instigantes e ornados de cílios postiços, delineador, sombra, base e corretivo. Histórias por trás de rostos extremamente maquiados, histórias criadas e vividas por estes mesmos rostos. Ou outros. Afinal, toda vez que aparecem em público, apresentam um rosto novo. Estes são alguns elementos que podemos citar como referências às características marcantes das drag queens: artistas que têm ganhado mais espaço nos últimos anos, tanto no Brasil quanto em vários outros lugares do mundo.

Mas o que entendemos ser uma drag queen? Amanajás (2014), ao traçar um percurso histórico pela arte dos atores transformistas, sinaliza que, apesar de ser uma figura muito presente entre gays, a drag queen é uma forma de arte que não estabelece correlação direta com identidade de gênero e sexualidade. Ao mesmo tempo, é uma expressão artística permeada por fatores sexuais, políticos e sociais, que passou por inúmeras transformações e atualizações, e tem se deslocado de uma posição marginalizada para um terreno mais conhecido, sobretudo na última década.

Já Jesus (2012) afirma que as drag queens consistem em artistas homens que se fantasiam de mulheres e fazem uso de uma feminilidade exagerada e estereotipada como forma de espetáculo e entretenimento, vivenciando a inversão do gênero sem reivindicá-la para si. Nesta concepção, nota-se a construção de uma personagem que não necessariamente possui relação

\footnotetext{
${ }^{1}$ Universidade Federal do Espírito Santo, Vitória, ES, Brasil.

${ }^{2}$ Universidade Federal do Espírito Santo, Vitória, ES, Brasil.
} 
com a identidade de gênero ou orientação sexual de quem a constrói. Vencato (2002) contribui para a discussão ao dizer que, em relação às drags, o processo de construção de uma personagem é gradativo e inovador, iniciando-se na primeira montação e se reelaborando a cada vez que entra em cena algum aspecto relacionado ao fazer drag.

Apesar da tentativa de uma certa conceituação, tanto Amanajás (2014) quanto Jesus (2012) e Vencato (2002) alegam que não há consenso ou definição única no que se refere às drag queens. Tendo em vista que o fazer drag e suas reverberações se dão em diferentes situações e contextos, é possível observar o envolvimento de processos de subjetivação, dessubjetivação, inovação, provocações e outros tantos elementos, impossibilitando a criação de definições exatas ou enclausuramentos em relação a este fazer artístico.

Em vez de tentar fechar conceitos sobre as drag queens, ao traçar algumas pistas dos desdobramentos da performance drag, podemos expandi-los. Adotando a montação como ponto de partida de nossa análise, percebemos que através dela entram em cena os contornos, as cores, os desenhos das sombras espalhadas no rosto, o tamanho e espessura do delineador, a curvatura dos cílios, das sobrancelhas e o volume dos lábios. Os enchimentos, as vestimentas, incontáveis combinações de jogos de luzes e de texturas que produzirão diferentes silhuetas também são pontos muito bem explorados pelas drags.

Montar-se implica arquitetar o próprio corpo: uma engenharia somática que se ocupa em reconceber o corpo abandonando ideias de certo ou errado. A montação, como já traz em seu nome, implica ação. Então, trata-se também de algo temporário. Ao mesmo tempo, é difícil afirmar onde exatamente começa e onde termina o processo de se montar. O início é na escolha do nome? No planejamento, compra e costura das roupas? É quando a maquiagem começa a ser feita antes de algum show ou aparição? Talvez todas essas alternativas.

Da mesma forma, como podemos afirmar quando a montação acaba? Talvez essa seja uma questão um pouco mais contornada, visto que ao fim de seus trabalhos, muitas drags retiram toda a maquiagem e roupa que estavam usando enquanto montadas, referindo-se a este processo como "se desmontar". Mesmo assim, isto não é um consenso, uma vez que algumas pessoas fazem fronteiras bem definidas entre a vivência em drag e fora de drag, esses limites são mais nebulosos para outras, como vimos em alguns relatos no trabalho de Vencato (2002).

Para além do processo de montação, a performance drag, de modo geral, pode ser caracterizada como fazer que cunha traços de criação e expansão. Performar implica atividade, elaboração que não se restringe aos palcos e apresentações. A performance também está no cotidiano, nos materiais selecionados para roupas e maquiagens, nas fotografias publicadas nas redes sociais, nos vídeos gravados, no modo de falar e andar entre o público em uma festa, nos movimentos das mãos, nos olhares, nas maneiras de perceber e manipular o próprio corpo na relação com os outros e consigo, e em tantos outros contextos.

Ainda que feita pela mesma artista, uma performance nunca é igual a outra. A cada vez que surge, traz consigo uma novidade, e todas elas utilizam variadas tecnologias, mecanismos e engenhosidades para se sustentarem. Além de todos os aspectos da montação, as luzes, o palco, a arquitetura do ambiente, a disposição do espectador, o movimento do artista e outros elementos que circundam o corpo também compõem atos performáticos. A performance drag não é algo rígido e mecanizado, pois é feito no encontro da artista com a arte, com os espectadores e com o próprio desejo. Conta com olhares, gritos, sons, expressões faciais, movimentos, prazeres, desafios, amores, ódios, desconfianças, dores e, evidentemente, com a imprevisibilidade da vida.

Essa dinâmica atravessa e é atravessada por diferentes linhas, que consistem em movimentos de diferenciação, fluxos e relações de sentido e força que traçam inúmeras formas de viver e caotizam os modos vigentes. Deleuze e Guattari (1996) indicam a existência de três tipos de linhas: linhas de segmentaridade rígidas, linhas maleáveis e linhas de fuga. As linhas 
de segmentaridade rígidas estão presentes em diferentes contextos ao longo da história das sociedades e são caracterizadas por relações que parecem previsíveis e contáveis.

As linhas de segmentaridade rígidas são linhas de controle que buscam garantir ordem, formatando grandes grupos bem delimitados na malha social, estratificações de classe, sexo, gênero, raça e outras. É interessante ressaltar que tanto estas quanto as demais linhas não podem ser separadas umas das outras, ou classificadas de maneira positiva ou negativa, pois cada uma delas propicia diferentes experimentações para diferentes formas de vida (DELEUZE; GUATTARI, 1996; CASSIANO; FURLAN, 2013).

Já nas linhas de segmentaridade maleável não existem núcleos que comandem as relações e os fluxos, mas rachaduras e impulsos que permitem maior fluidez e flexibilidade dos movimentos que ocorrem na imanência da vida. Diferente das linhas duras com fluxos prédeterminados, aqui temos um funcionamento rizomático (DELEUZE; GUATARRI, 1996). Neste caso, não há preocupação com a origem e a finalidade dos elementos, mas sim com os meios, sendo chamado de acontecimentos os momentos em que a realidade é construída. Apesar de haver uma pressão para que estas linhas se enquadrem em um modelo rígido, os acontecimentos despontam em uma desestratificação, escapando do controle de grandes sistemas (CASSIANO; FURLAN, 2013).

As linhas de fuga, terceira denominação atribuída por Deleuze e Guattari (1996), são imprevisíveis, imperceptíveis e, ao mesmo tempo, extremamente ativas. Engendram mudanças bruscas que não podem ser codificadas pelas linhas mais rígidas, tampouco pelas maleáveis. As linhas de fuga promovem rupturas que nos lançam em experimentações e acontecimentos, uma vez que desfazem o eu de relações já estabelecidas. Assim como as outras duas modalidades que descrevemos, as linhas de fuga se entrecruzam e se misturam, seja momentaneamente ou a longo prazo, sempre provocando interferências umas nas outras. Vale ressaltar que não é incomum uma linha se transformar em outra, já que fluxos maleáveis podem se apoiar em pontos de maior rigidez e vice-versa (CASSIANO; FULAN, 2013).

Existem infinitas modalidades e estilos que as drags manejam, brincam, criam, transformam e adotam, e em cada um deles há uma rica articulação, exploração e produção de diferentes linhas que permeiam suas existências. Todos os estilos são performados por pessoas que, na malha social, sustentam cor, gênero, sexualidade, situação econômica e outros fatores que são encaixados em segmentaridades mais rígidas. O gênero, por exemplo, é um dos elementos mais explorados pelas drags, que o dobram, destroem, inventam, modificam e satirizam, trincando saberes petrificados e costurando possibilidades mais fluidas.

As linhas de segmentaridade maleáveis e as linhas de fuga se presentificam nos mais diversos detalhes da performance drag queen. O impossível pode ser maquiado e transformado em horror, espanto ou admiração. Podemos contemplar artistas que produzem maquiagens monstruosas, fantasmagóricas, alienígenas, imitações de famosas obras de arte e invenção de muitas outras. Também é possível localizar drags que se apoiam em uma estética voltada à noção comum de feminino, trazendo consigo discussões sobre estereótipos, fenótipos femininos e masculinos, normas sociais e papeis de gênero.

Ao atravessar e ser atravessada por diferentes modos de funcionamentos, tanto já existentes quanto novas possibilidades, a performance drag implica o que pode ser nomeado território. O entendimento de território pode ser relativo a um espaço ou sistema em que o sujeito sente-se “em casa": como modalidades de organização que delimitam e articulam os seres existentes uns aos outros e aos fluxos cósmicos. Os territórios fazem emergir uma série de investimentos e comportamentos em espaços culturais, estéticos, cognitivos, sociais e até mesmo temporais (GUATARRI; ROLNIK, 1996). 
Uma vez construído o território, estamos sujeitos a movimentos de desterritorialização. Tais movimentos dizem respeito ao processo de aderência às linhas de fuga, ocorrendo uma abertura e, até mesmo, a destruição do atual território, instaurando algo radicalmente novo. Existem várias drag queens que afirmam ter experienciado grandes mudanças em diversos âmbitos de suas vidas, como na forma que se sentem fazendo drag ou no modo de enxergar o próprio corpo e vivenciar o gênero. O público, ou espectador, também pode mergulhar em processos que podem desembocar numa desterritorialização, afinal, a performance, apesar de singular, nunca é individual, e possui reverberações de caráter coletivo e imprevisível (HAESBAERT; BRUCE, 2001).

Também é interessante pontuar os movimentos de reterritorialização, que consistem em tentativas de se apropriar de um território após um processo de desterritorialização. Aqui, existe o perigo de encarar a reterritorialização como um retorno ao "território original" ou anterior, ou até mesmo uma tentativa de copiar o que outrora configurou um território. Isto é impossível. Trata-se, na verdade, de nos servirmos de elementos de desterritorialização para construir uma nova territorialidade, em um processo de invenção de si que, neste caso, não raramente comparece na experiência das drag queens (HAESBAERT; BRUCE, 2001).

A construção de territórios é feita por meio de diferentes agenciamentos, que podem ser classificados em agenciamentos maquínicos de corpos e agenciamentos coletivos de enunciação. Enquanto o primeiro diz sobre as máquinas sociais e a mistura entre os corpos nas sociedades, os agenciamentos coletivos de enunciação se referem a um conjunto de signos compartilhados que só podem se efetivar na dimensão coletiva, como a linguagem e símbolos. Haesbaert e Bruce (2002) enfatizam a relevância de ter em vista que essas duas modalidades de agenciamentos não se opõem uma à outra, mas se percorrem, se influenciam e se atravessam.

É visível no fazer drag que essas faces de agenciamento não se separam: aspectos corporais comportam expressões e linguagens, assim como os diferentes tipos de expressões, apresentações, dialetos e símbolos que as drag utilizam se presentificam no corpo. Apresentações com danças que carregam em si uma história, como o vogguing, nomes que, em sua sonoridade, apresentam piadas de duplo sentido, sátiras e críticas políticas feitas em apresentações ou até mesmo embutidas na própria vestimenta, são exemplos que revisitam essas faces de agenciamentos nos trabalhos das drag queens.

Podemos concluir, então, que o corpo configura o mais escandaloso território na performance drag, e por isso está sujeito a movimentos de desterritorialização e reterritorialização. O fazer drag ocupa-se de uma degustação corporal, onde a dimensão somática é a superfície inserida na realidade que produzirá estranhamento, admiração, fascínio, repulsa e outros diferentes sentimentos e sensações, tanto no espectador, que lê e interpreta a artista, quanto na própria artista. É pelo corpo que falamos, nos relacionamos, vestimos, ocupamos espaços, expressamos e sentimos afetos.

Cada drag queen emerge em meio a um cenário político, estético, econômico, racial, geográfico e sexualizado. A partir destes e de outros fatores criam-se modos únicos de existência, de se fazer arte e de contar sua história. Esses modos são recheados de nuances que constroem a performance drag, que, por sua vez, é constantemente atravessada por linhas de força, brecha, fissura, fratura, visibilidade e enunciação, apresentando entrecruzamentos e multiplicações, e criando também multiplicidades. É vivendo em meio a toda essa complexidade que as drag queens são grandes produtoras de si e de diversas realidades.

\section{Referências}

AMANAJÁS, I. Drag Queen: um percurso histórico pela arte dos atores transformistas. Revista Belas Artes, São Paulo, v. 16, p. 1-23, 2014. 
CASSIANO, M.; FURLAN, R. O processo de subjetivação segundo a esquizoanálise. Psicologia \& Sociedade, Belo Horizonte, v. 25, n. 2, p. 373-378, 2013.

HAESBAERT, R.; BRUCE, G. A desterritorialização na obra de Deleuze e Guattari. GEOgraphia, Niterói, v. 4, n. 7, p. 7-22, 2001.

GUATTARI, F.; ROLNIK, S. Micropolítica: Cartografias do desejo. Petrópolis: Vozes, 1996.

JESUS, J. Gomes. Orientações sobre identidade de gênero: conceitos e termos. Brasília, 2012. Disponível em: https://files.cercomp.ufg.br/weby/up/16/o/ORIENTA\%C3\%87\%C3\%95ES_POPULA\%C3\% 87\%C3\%830_TRANS.pdf?1334065989. Acesso em: 15 de fev. de 2021.

VENCATO, A. P. Fervendo com as drags: corporalidades e performances de drag queens em territórios gays da Ilha de Santa Catarina. 2002. Dissertação (Mestrado em Antropologia) Departamento de Antropologia Social, Universidade Federal de Santa Catarina, Florianópolis, 2002.

\section{Sobre os autores}

Matheus Flauzino Oliari é estudante de psicologia na Universidade Federal do Espírito Santo, tem experiência na área de psicanálise e estudos sobre subjetividade, com pesquisa nos seguintes temas: diversidade sexual e de gênero.

E-mail: matheusflauzino14@gmail.com.

Jesio Zamboni. Graduado em Psicologia, Mestre em Psicologia Institucional e Doutor em Educação pela Universidade Federal do Espírito Santo (UFES). Professor Adjunto do Departamento de Psicologia e Professor Permanente do Programa de Pós-Graduação em Psicologia Institucional (PPGPSI) da UFES.

E-mail: zambonijesio@gmail.com. 